www.jmscr.igmpublication.org

Index Copernicus Value: 79.54

ISSN (e)-2347-176x ISSN (p) 2455-0450

crossrefDOI: https://dx.doi.org/10.18535/jmscr/v7i1.143

\title{
Correlation of BMI and Neck circumference with severity of AHI in patients with Obstructive Sleep Apnea
}

\author{
Authors \\ Dr Jayagar Prabakaran, MBBS, MPH (USA), MS (ENT) ${ }^{1}$, Dr T.Bindu, MBBS, MD $^{2}$ \\ ${ }^{1}$ Assistant Professor- Department of ENT, Tagore Medical College and Hospital, Chennai- 127 \\ ${ }^{2}$ Associate Professor, Dept of Respiratory Medicine, Tagore Medical College and Hospital, Chennai-127 \\ Corresponding Author
}

Dr T. Bindu, MBBS, MD

Associate Professor Department of Respiratory Medicine, Tagore Medical College and Hospital,

Chennai-127, India

Email: drjayagar@gmail.com, Phone: 9445888767

\begin{abstract}
Obesity being identified as a common risk factor for sleep related breathing disorder, measuring certain physical parameters in obese patients help us in identifying Obstructive Sleep Apnea (OSA) suspects at the earliest. The objective of this study is to find out the correlation of Body Mass Index (BMI) and Neck circumference (NC) with severity of AHI in patients with OSA.
\end{abstract}

Material \& Methods: 50 consecutive patients suspected to have OSA, attending OPD were enrolled. BMI and NC recorded. AHI was calculated by over-night full polysomnography and correlation of severity of AHI with BMI and NC explored.

Results: Out of 50 cases analysed, 35 were men and mean (SD) age was $48.6 \pm 6.2$ years. $28 \% .44 \%$ and $28 \%$ had mild, moderate and severe OSA respectively based on AHI values. $56 \%$ had BMI more than 30 and NC more than $40.2 \mathrm{~cm}$ was seen in $38 \%$ patients.

Conclusion: BMI and NC had significant correlation with severity of AHI, $p$ value being 0.010 and 0.001 respectively. NC had a stronger positive correlation with severity of OSA, when compared with BMI.

Keywords: OSA, BMI, Neck Circumference.

\section{Introduction}

Obstructive sleep apnea is commonly seen in obese individuals and is defined by AHI $>5$ times per hour of sleep, detected by polysomnography. OSA has a slight male preponderance with its prevalence being $4 \%$ in males and $2 \%$ in females. (1-3). Multiple factors like BMI, body fat distribution particularly neck fat deposition, pharyngeal muscle one does have a relationship with pathogenesis as well as severity of OSA. ${ }^{(4-7)}$. Polysomnography is currently the gold standard investigation to diagnose and grade the severity of OSA. The aim of this study is to find out the correlation between BMI and NC with severity of OSA, as these parameters would help clinicians in selecting patients for polysomnography. 


\section{Material \& Methods}

We enrolled 50 consecutive patients with history of snoring or clinically suspected OSA attending OPD of respiratory medicine/ENT department in a tertiary care centre.

\section{Inclusion criteria}

- $\quad$ Age $\geq 18$ years and $\leq 65$ years

- History of snoring

- Date time somnolence

- Willing to take part in study

\section{Exclusion criteria}

- Cardio-vascular disease, cerebro vascular accident, neuro-muscular diseases

- Cranio-facial anomalies

- Hypothyroidism, acromegaly, vocal cordpalsy

- Amyloidosis

Clinical data and anthropometric data (BMI+NC) recorded. NC measured at upper border of cricothyroid membrane in each patient at sitting posture. BMI and NC were graded. OSA severity was classified based on AHI into mild (AHI=515 times $/ \mathrm{hr}$ ), moderate (AHI=15-30times $/ \mathrm{hr}$ ) and severe (AHI> 30times/hr) reported by full nocturnal polysomnography.

\section{Statistical Analysis}

Done using SPSS (Statitical package for Social Sciences) version 21 and $\mathrm{p}$ value $<0.05$ was considered significant. Categorical data compared using chi-square test.

Working Definitions

a. BMI $\left(\mathrm{kg} / \mathrm{m}^{2}\right)$ :

Underweight $\quad-<18.5$

Normal $\quad-18.5-24.9$

Overweight $\quad-25-29.9$

Obese I $\quad-30-34.9$

Obese II $\quad-35-39.9$

Morbidly obese III - $\geq 40$

b. Neck circumference $(\mathrm{cm})$

I - 32-36

II $-36.1-40.1$

III $-\geq 40.2$

c. AHI (times/hr):

Mild: 5-15

Moderate: 16-30

Severe : >30

\section{Results}

Table 1: Descriptive data $(\mathrm{n}=50)(\%)$

\begin{tabular}{|c|c|c|}
\hline $\begin{array}{ll}B & M \\
\left(\mathrm{~kg} / \mathrm{m}^{2}\right) & \end{array}$ & $\begin{array}{c}<18.5 \\
18.5-24.9 \\
25-29.9 \\
30-34.9 \\
35-39.9 \\
\geq 40\end{array}$ & $\begin{array}{c}3(6 \%) \\
6(12 \%) \\
13(26 \%) \\
10(20 \%) \\
9(18 \%) \\
9(18 \%)\end{array}$ \\
\hline 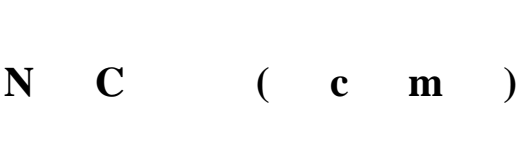 & $\begin{array}{c}32-36 \\
36.1-40.1 \\
\geq 40.2\end{array}$ & $\begin{array}{l}10(20 \% \\
21(42 \%) \\
19(38 \%)\end{array}$ \\
\hline AHI ( no. of times/hr. of sleep) & $\begin{array}{c}5-15 \\
16-30 \\
>30\end{array}$ & $\begin{array}{l}14(28 \%) \\
22(44 \%) \\
14(28 \%)\end{array}$ \\
\hline
\end{tabular}


Table 2: Relationship between BMI and NC with severity of AHI $(\mathrm{n}=50)$

\begin{tabular}{|c|c|c|c|c|c|c|c|}
\hline & A H I $(5-15)$ & AHI $(16-30)$ & A H I $(>30)$ & $\mathrm{Chi} \mathrm{square}$ & $\mathrm{P}$ & $\mathrm{v}$ a $1 \mathrm{u}$ & $\mathrm{e}$ \\
\hline $\begin{array}{l}\mathbf{B} \quad \text { M } \\
<18.5 \\
18.5-24.9 \\
25-29.9 \\
30-34.9 \\
35-39.9 \\
\geq 40\end{array}$ & $\begin{array}{l}2(4 \%) \\
3(6 \%) \\
3(6 \%) \\
2(4 \%) \\
2(4 \%) \\
2(4 \%)\end{array}$ & $\begin{array}{c}1(2 \%) \\
2(4 \%) \\
8(16 \%) \\
5(10 \%) \\
3(6 \%) \\
3(6 \%)\end{array}$ & $\begin{array}{c}- \\
1(2 \%) \\
2(4 \%) \\
3(6 \%) \\
4(8 \%) \\
4(8 \%)\end{array}$ & $\begin{array}{lll}1 & 3 & 7\end{array}$ & 0 & $\begin{array}{ll}0 & 1\end{array}$ & 0 \\
\hline $\begin{array}{ll}\mathbf{N} & \mathbf{C} \\
32-36 & \\
36.1-40.1 \\
\geq 40.2\end{array}$ & $\begin{array}{l}7(14 \%) \\
4(8 \%) \\
3(6 \%)\end{array}$ & $\begin{array}{c}2(4 \%) \\
12(24 \%) \\
8(16 \%)\end{array}$ & $\begin{array}{c}1(2 \%) \\
5(10 \%) \\
8(16 \%)\end{array}$ & $\begin{array}{llllll}4 & 2 & . & 3 & 4 & 0\end{array}$ & 0 & $\begin{array}{ll}0 & 0\end{array}$ & 1 \\
\hline
\end{tabular}

Mean age of study group was $48.6 \pm 6.2$ years and $35(70 \%)$ of them were males. 36 participants had AHI more than 15 times/hr of sleep, BMI >30 seen in $28(56 \%)$ patients and NC> 40.2 was observed in 19 (38\%) individuals (Table 1).

Relationship between BMI and NC with AHI is depicted in table 2. Though BMI and NC both had positive correlation with severity of AHI, strongest positive relationship was found between increased neck circumference and AHI severity ( $p$ value 0.001 ).

\section{Discussion}

Neck circumference, BMI and waist circumference are parameter used to assess obesity and many studies have demonstrated increased neck circumference in patients who snore, have $\operatorname{OSA}^{(9)}$. In this study, the most affected population was working adult males, which is in accordance with the large epidemiological study done by Lurie ${ }^{(10)}$. BMI had a positive correlation with severity of AHI. Chang et al also derived similar results from the study and concluded that BMI should be considered as a marker for OSA severity ${ }^{(11)}$. Patients with increased neck circumference had more severe OSA in our study which was statistically significant ( $p$ value 0.001). Studies done by Medeiros and Pinto et al in western population showed that neck circumference was the most significant factor which had an association with severity of OSA than BMI, a finding similar to results derived in our study. Assessing simple physical parameters like BMI and NC is needed in all obese patients and regional distribution of fat has more significance when compared with total body fat as far as OSA is concerned.

\section{Conclusion}

Our study suggests that both BMI and NC are significant determinants of severity of OSA. Neck fat deposition rather than generalized obesity is an important independent determinant of sleep apnea. These parameters can only be used as screening test for OSA, the gold standard investigation still being polysomnography. In resource limited facilities without polysomnography equipments, parameters like BMI and NC measurements help clinicians to select ideal candidates in whom sleep study is warranted.

\section{References}

1. Young T, Palta M, Dempsey J, Skatrud J, Weber S, et al. (1993) The occurrence of sleep-disordered breathing among middleaged adults. N Engl J Med 328: 12301235.

2. Kyzer S, Charuzi I (1998) Obstructive sleep apnea in the obese. World J Surg 22: 998-1001.

3. Dixon JB, Schachter LM, O'Brien PE (2003) Predicting sleep apnea and excessive day sleepiness in the severely obese: indicators for polysomnography. Chest 123: 1134-1141. 
4. Davies RJO, Stradling JR. - The relationship between neck circumference, radiographic pharyngeal anatomy, and the obstructive sleep apnea syndrome. EurRespir J, 1990; 3: 509-514.

5. Rodenstein DO, Dooms G, Thomas Y, Liistro G, Stanescu DC, Culee C, AubertTulkens G. - Pharyngeal shape and dimensions in healthy subjects, snorers, and patients with obstructive sleep apnea. Thorax, 1990; 45: 722-727.

6. Polo OJ, Tafti M, Fraga J, Porkka KVK, Dejean Y, Billiard M. - Why don't all snorers have obstructive sleep apnea? Am Rev Respir Respir Dis, 1991; 143: 12881293.

7. Hoffstein V, Wright S, Zamel N, Bradley TD. - Pharyngeal function and snoring characteristics in apneic and 381 nonapneic snorers. Am Rev RespirDis, 1991; 143: 1294-1299.

8. Rodsutti J, Hensley M, Thakkinstain A, D'Este C, Attia J. A clinical decision rule to prioritize polysomnography in patients with obstructive sleep apnea. Sleep. 2004;27:694-9.

9. The correlation of physical parameters and apnoeahypoapnoea index in OSA suspected Thai patients. Nuntigar et.al. Journal of sleep disorders and therapy. Vol 2,Issue 3.2013.

10. Lurie A. Obstructive sleep apnea in adults: epidemiology, clinical presentation, and treatment options. Adv Cardiol. 2011;46:1-42.

11. Chang ET, Yang MC, Wang HM, Lai HL. Snoring in sitting position and neck circumference are predictors of sleep apnea in chineses patients. Sleep Breath. 2014;18(1):133-6.

12. Medeiros CA, Bruin VM, Castro-Silva Cd, Araújo SM, Chaves Junior CM, et al.
(2011) Neck circumference, a bedside clinical feature related to mortality of acute ischemic stroke. Rev Assoc Med Bras 57: 559-564.

13. Pinto JA, Godoy LB, Marquis VW, Sonego TB, Leal Cde F, et al. (2011) Anthropometric data as predictors of Obstructive Sleep Apnea Severity. Braz J Otorhinolaryngol 77: 516-521. 